\title{
AiMT
}

Advances in Military Technology

Vol. 12, No. 2 (2017), pp. 259-280

ISSN 1802-2308, eISSN 2533-4123

DOI 10.3849/aimt.01186

\section{Wearable Systems and Methods for Monitoring Psychological and Physical Condition of Soldiers}

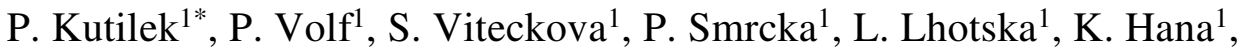 \\ V. Krivanek ${ }^{2}$, R. Doskocil ${ }^{2}$, L. Navratil ${ }^{1}$, Z. Hon ${ }^{1}$ and A. Stefek ${ }^{2}$ \\ ${ }^{1}$ Faculty of Biomedical Engineering, Czech Technical University in Prague, Czech Republic \\ ${ }^{2}$ Faculty of Military Technology, University of Defence in Brno, Czech Republic
}

\begin{abstract}
The manuscript was received on 20 March 2017 and was accepted after revision for publication on 17 November 2017.
\end{abstract}

\begin{abstract}
:
From the second half of the 1990s, thanks to more affordable and more powerful information technology and electronical systems for recording based on miniaturized sensors, we can observe a more intensive development of a method of data analysis and a system that monitors the physical and psychological conditions of soldiers. Systems for measuring and evaluation methods of physical and medical data for the diagnostics of physical and psychological state have significantly spread, especially in clinical practice. This study, however, examines the current technologies and usage of the wearable monitoring systems in military field. The result of this study is not only the not-yet published summary of the current state, but also the proposed possibilities of usage and recommendation of specific systems, their sensors and system methods in the military. Thus, the article can serve as a guide for choosing suitable and affordable electronical wearable systems and methods of quantitative evaluation of physical and psychological conditions of people in the military.
\end{abstract}

\section{Keywords:}

physical state, psychological state, monitoring, army, health condition, wearable systems

\section{Introduction}

The spread in the use of wearable systems and methods for evaluating physical and psychological conditions of subjects can be traced back to the half of the 1990s, thanks to the technology and electronic measuring systems based on new miniaturized sensors. The most frequent use of analysis of the condition for the diagnostics of physical and mental health can be found in medicine in the civilian sphere. Nevertheless, analysis of medical conditions may find use not only in civilian sphere, but also in several areas of military environment, such as:

\footnotetext{
* Corresponding author: Patrik Kutílek, Faculty of Biomedical Engineering, Czech Technical University in Prague, Sitna sq. 3105, 27201 Kladno, Czech Republic. Phone: +420 72351 12 42, E-mail: kutilek@fbmi.cvut.cz
} 
1. diagnostics of health, physical and mental readiness

○ of applicants for military service in military hospitals;

- of soldiers before sending them to foreign missions, or before that, in military hospitals and infirmaries;

$\circ$ and stress in small medical centres during special long-term or shortterm trainings;

○ and stress of soldiers in small medical centres (in a combat area of operations) during military missions;

○ of soldiers directly during long-term or short-term trainings and military missions independently of any medical centres;

o of soldiers or veterans in military or civil medical centres (or home in the case of distance medicine) during treatment and rehabilitation;

2. evaluation of progress or deterioration in physical and psychological state in the scope of the development of new assistive technology (prosthetic or orthotic devices etc.) for soldiers and veterans.

Wearable systems may be used directly to record quantities describing health condition of subjects, followed by an immediate evaluation of the data, during training by biofeedback using PC, both in the course of rehabilitation, training of soldiers or during the combat mission. The objective of the article is the analysis of the recent state of the use of wearable systems in the military field. Due to this, the article is divided into two main parts: the research of the use of systems and the research of the use of methods of quantitative evaluation of the data from systems measuring the physical and psychological conditions. Article presents an overview of the recent state of the application of systems and methods of evaluation of health condition in military sphere. The article also presents the current state of development of systems in the Army of the Czech Republic and recommends specific conceptions of systems and methods. The article thus may be a tool for choosing appropriate electronic wearable systems and methods of quantitative evaluation of physical and psychological conditions of people in the military field.

\section{Overview of Current Systems and Methods}

Systems based on specific sensors and suitable methods of quantitative evaluation of measured data are developed and tested for monitoring physical and psychological conditions of soldiers. In this part of the article, we will briefly introduce the current state of development of wearable systems for military application, an overview of used or tested sensors of wearable systems and list the basic division of applied methods of measured data evaluation.

\subsection{Division of Current Wearable Systems}

Currently, there are several wearable systems, which differ in technical design, but in most cases, they are modular systems that use specific sensors that allow monitoring of specific parameters based on demands of its usage. Many research projects were devoted to the design of general-purpose or medical body sensor solutions in the last decade [1-9], as well as recent research projects are [10-15]. The target groups are, apart from armed forces, fire departments, emergency medical services and other rescue services. Specifications (i.e. the use of specific sensors) and their use within the various groups may differ. Some agencies need to monitor many parameters (e.g. temperature, presence of specific Chemical, Biological, Radiological and Nuclear (CBRN) substances in the 
air, etc.), which is possible due to the modularity of majority of the available systems. Such wearable systems are called Wireless Body Area Network (WBAN) or a body sensor network (BSN). For the application in armed forces, the systems are formed by small electronic devices placed on a body of a soldier. The function of these sensors is to obtain, convert, transmit and receive a specific signal, which is captured by specific sensors, which are chosen appropriately to the monitored environment. These sensors not only complexly monitor physiological values and health condition of soldiers, but also monitor their physical load and other factors that lead to the identification of hazardous conditions.

Wireless body systems are generally grouped into [16]:

1. off-body, the device is located on the body and communicates with one (or more) devices located off-body;

2. on-body, a number of devices is located on the body and they communicate with each-other;

3. in-body, the devices are implanted (some or all of them).

Types of BSN devices can be grouped into [17]:

1. (wireless) sensor node: responds and gathers data on vital signal / physical stimuli, processes the data (if necessary) and reports this information wirelessly;

2. (wireless) actuator node: acts according to the data received from the sensors or through an interaction with the user;

3. (wireless) personal device (also called a Body Control Unit): gathers all the information acquired by sensors and actuators and informs the user.

All the previously listed types / groups of a basic wearable system division can find an application in civilian as well as in military environment. According to the focus of this article (i.e. the use of wearable systems in military practice to monitor physical and psychological conditions of a soldier during a mission), the rest of the paper focuses on suitable types of sensors nodes communicating off-body.

\subsection{Current Wearable Sensors Division}

In this part, a main overview of current sensors which are tested or already used in the developed wearable systems, is listed.

\section{Heart Rate Sensors}

Basic sensor for monitoring [18-20]. Depending on the type, the sensor must usually be in contact with a body segment (i.e. skin) and is placed on trunk or limbs with adhesive. Based on heart rate, you can infer, for example, the stress and physical exertion of a soldier [21].

\section{Electrocardiogram Sensors}

Sensors sense the small amplitude electrical signals associated with heart contractions and heart irregularities. ECG analysis by portable sensors is not meant to perform a detailed clinical diagnosis, but to provide an understanding of health status or to aid in life-sign detection $[22,23]$. The sensor must be in contact with a body segment (i.e. skin) and is placed on trunk with adhesive. It provides more detailed information about the state of heart than the Heart rate sensor.

\section{Electroencephalography Sensors}

Sensors for monitoring brain electrical activity are used, for example, in an intelligent helmet [23-25]. They provide information for monitoring the vital signs and brain damage. Apart from that, they can also provide information about the effect of 
sedative / anaesthesia in patients in medically induced coma. The sensor must be in contact with a body segment (i.e. skin) and is placed on head.

\section{Respiratory Rate Sensors}

Respiratory rate is the number of breaths per minute or, more formally, the number of movements indicative of inspiration and expiration per time unit. The aim of measuring respiratory rate is to determine whether the respirations are normal, abnormally fast, abnormally slow or non-existent $[26,27]$. Depending on the type, the sensor may or may not be in contact with a body segment (i.e. trunk).

\section{Blood Pressure Sensors}

The sensors measure human blood pressure. They usually measure systolic, diastolic and mean arterial pressure. Some of them also measure pulse rate $[19,25,28]$. Therefore, they provide information about physical and psychological condition of the subjects, which is, for example, stress or a severity of an injury. Depending on the type, the sensor must usually be in contact with a body segment (i.e. skin) and is placed on trunk or limbs.

\section{Pulse Oximetry Sensors}

Sensors used to measure the blood oxygen saturation $\left(\mathrm{SpO}_{2}\right)[29,30]$. The device measures the oxygen consumption, and therefore is used to monitor the physical and psychological load. Depending on the type, the sensor must usually be in contact with the segment of the body and is located on the limbs.

\section{Other Photoplethysmographic Sensors}

With these sensors and with good calibration, it is possible to determine not only the oxygen saturation of blood, but also, for example, the blood pressure from the photoplethysmogram. As with all measured parameters, the relative change from the values in resting condition and under load is important [31]. Depending on the type, the sensor must usually be in contact with the segment of the body and is located on the limbs.

\section{Thoracic Electrical Bioimpedance Sensors}

The system measures cardiac output and other hemodynamic parameters [32]. By measuring these parameters, the system allows us to monitor the physical and psychological condition of subjects. Depending on the type, the sensor must usually be in contact with a body segment (i.e. skin) and is placed on limbs.

\section{Electrooculography Sensor / Eyeblink Sensor}

It allows us to measure the eye movement and intensity of blinking, the sensors are used, for example, in an intelligent helmet [23, 24]. The eye movement allows us to determine, for example, the stress or fatigue of the subject. The sensor does not need to be, depending on the type, usually in contact with a body segment and is located on the head in the proximity of the eyes.

\section{Acoustic Sensors}

They allow us to evaluate thoracic sounds / trauma, speech, etc. [33]. This allows us to monitor the condition of a soldier. The premise is the use of expert system for the automated determination of the status of the subjects based on the audio recording. The sensor does not need to be, depending on the type, usually in contact with a body segment and is located in the proximity of the trunk or head.

\section{Electromyography Sensors}

An electromyograph detects the electric potential generated by muscle cells when these cells are electrically or neurologically activated $[25,34]$. The sensor must be in contact with a body segment (i.e. skin) and is placed on trunk or limbs with adhesive. 


\section{Temperature Sensors}

One of the most used sensors in systems monitoring soldier's conditions are the body temperature sensors $[18,20,22]$. The parameters of soldiers are usually measured continuously and wirelessly transmitted. Sensors not only can measure the health condition, but also the conditions of the environment, where the activity is carried out. Depending on the type, the sensor must usually be in contact with a body segment (i.e. skin) and is placed on trunk or limbs.

\section{Galvanic Skin Response Sensors}

Galvanic skin response represents electrical conductivity [33]. Skin conductivity is affected by the sweat from physical activity and by emotional stimuli. Sensors can measure evaporative heat loss, etc. [35]. The sensor must be in contact with a body segment and is placed on trunk or limbs.

\section{Perspiration Sensors}

Measuring the intensity of sweating does not directly allow to determine the trauma, but it allows to determine the physical and psychological load of the subject, and therefore is a suitable complementary sensor [36-38]. Depending on the type, the sensor must usually be in contact with a body segment (i.e. skin) and is placed on trunk or limbs with adhesive.

\section{Motion Tracking Sensors}

Primarily based on accelerometers, but also on gyroscopes, these sensors are used for the determination of a physical activity that is specified by a development of acceleration or by a change in orientation of the body segments in space $[18,25]$. The sensor does not usually need to be in direct contact with a body segment and is placed by trunk, head or limbs with adhesive.

\section{Strain Gauge Sensors}

Sensors that allow to determine weight load, walk ratio (step length/cadence), pose, etc. [33]. By using an expert system, it is possible to determine the soldier's activity, or identify the type of the injury based on the load distribution on the limbs, etc. Depending on the type, the sensor may or may not be in contact with a body segment and is located under the limbs.

\section{pH Level Sensors}

Sensors that allow to determine the overall health condition based on skin surface $\mathrm{pH}$. The acid reaction represents a defence mechanism of the skin surface. It is the least necessary sensor for monitoring the conditions [39]. The sensor must be in contact with a body segment (i.e. skin) and is placed on trunk or limbs with adhesive.

\section{Lactate Level Sensors}

The measuring is done, for example, using the mouthpiece in the form of a mouthguard, which analyses saliva by enzyme electrodes [40]. Another option is an analysis of tears by special contact lenses [41], or an analysis of sweat [42]. Depending on the type, the sensor must be in contact with a body segment and is placed by on trunk or limbs, or, eventually, in the oral cavity or in contact with the cornea.

\section{Glucose Level Sensors}

The measuring is done by analysing glucose in tears [43] or in sweat [38]. The sensor must be, depending on the type, in contact with a body segment (i.e. skin) and is placed on trunk or limbs with adhesive, or in a contact with the cornea.

\section{Other Electrochemical Sensors of Homeostasis}

Other wearable electrochemical sensors include sensors of uric acid [44], ammonium (high levels during metabolic alkalosis) [45], sodium [46]. Depending on the type, the sensor must usually be in direct contact with a body segment. 
The order of the selected sensor types is determined by the specific application goals. For example, if the primary intention is the life-sign detection, then it is important to monitor blood pressure and brain function. However, if the primary goal is to avoid heat-related injuries during training, temperature and galvanic skin response sensors are of primary importance. Heart rate, electrocardiogram sensors and respiration are, on the contrary, basic indicators for the study of the overall condition of the monitored subject. For a summary and a comparison of sensors, as described above, see Tab. 1.

Tab. 1 Overview of summary of sensors

\begin{tabular}{|c|c|c|c|}
\hline Sensor & $\begin{array}{l}\text { Measured } \\
\text { parameter }\end{array}$ & $\begin{array}{c}\text { Inferred } \\
\text { information }\end{array}$ & Body placement \\
\hline Heart rate sensors & heart rate & $\begin{array}{l}\text { immediate physical } \\
\text { and psychological } \\
\text { condition, overall } \\
\text { health condition, etc. }\end{array}$ & trunk, limbs \\
\hline $\begin{array}{c}\text { Electrocardiogram } \\
\text { sensors }\end{array}$ & $\begin{array}{c}\text { heart rate, heart rate } \\
\text { variability, etc. }\end{array}$ & $\begin{array}{l}\text { immediate physical } \\
\text { and psychological } \\
\text { condition, overall } \\
\text { health condition, etc. }\end{array}$ & trunk \\
\hline $\begin{array}{l}\text { Electroencephalog- } \\
\text { raphy sensors }\end{array}$ & entropy, power, etc. & $\begin{array}{l}\text { immediate psycho- } \\
\text { logical condition, } \\
\text { overall health condi- } \\
\text { tion }\end{array}$ & head \\
\hline $\begin{array}{l}\text { Respiratory rate } \\
\text { sensors }\end{array}$ & respiratory rate & $\begin{array}{l}\text { immediate physical } \\
\text { condition, overall } \\
\text { health condition }\end{array}$ & trunk, head \\
\hline $\begin{array}{c}\text { Blood pressure } \\
\text { sensors }\end{array}$ & blood pressure & $\begin{array}{l}\text { immediate physical } \\
\text { condition, overall } \\
\text { health condition }\end{array}$ & trunk, limbs \\
\hline $\begin{array}{c}\text { Pulse oximetry } \\
\text { sensors }\end{array}$ & $\begin{array}{l}\text { blood oxygen } \\
\text { saturation }\end{array}$ & $\begin{array}{l}\text { immediate physical } \\
\text { condition, overall } \\
\text { health condition }\end{array}$ & trunk, limbs \\
\hline $\begin{array}{l}\text { Other photoplethys- } \\
\text { mographic sensors }\end{array}$ & blood pressure, etc. & $\begin{array}{l}\text { immediate physical } \\
\text { condition, overall } \\
\text { health condition }\end{array}$ & trunk, limbs \\
\hline $\begin{array}{c}\text { Thoracic electrical } \\
\text { bioimpedance } \\
\text { sensors }\end{array}$ & blood pressure, etc. & $\begin{array}{l}\text { immediate physical } \\
\text { condition, overall } \\
\text { health condition }\end{array}$ & trunk \\
\hline
\end{tabular}




\begin{tabular}{|c|c|c|c|}
\hline Sensor & $\begin{array}{l}\text { Measured } \\
\text { parameter }\end{array}$ & $\begin{array}{c}\text { Inferred } \\
\text { information }\end{array}$ & Body placement \\
\hline $\begin{array}{l}\text { Electrooculography } \\
\text { sensor / eyeblink } \\
\text { sensor }\end{array}$ & eyeblink rate, etc. & $\begin{array}{l}\text { Immediate physical } \\
\text { condition, overall } \\
\text { health condition }\end{array}$ & head \\
\hline Acoustic sensors & respiratory rate, etc. & $\begin{array}{l}\text { Immediate physical } \\
\text { condition, overall } \\
\text { health condition }\end{array}$ & trunk, head \\
\hline $\begin{array}{c}\text { Electromyography } \\
\text { sensors }\end{array}$ & $\begin{array}{c}\text { electric potential } \\
\text { generated by muscle } \\
\text { cells, etc. }\end{array}$ & $\begin{array}{l}\text { immediate physical } \\
\text { condition, overall } \\
\text { health condition }\end{array}$ & trunk, limbs \\
\hline Temperature sensors & temperature & $\begin{array}{l}\text { immediate physical } \\
\text { and psychological } \\
\text { condition, overall } \\
\text { health condition }\end{array}$ & trunk, limbs \\
\hline $\begin{array}{l}\text { Galvanic skin re- } \\
\text { sponse sensors }\end{array}$ & skin conductivity & $\begin{array}{l}\text { immediate physical } \\
\text { condition, overall } \\
\text { health condition }\end{array}$ & limbs \\
\hline Perspiration sensors & relative humidity & $\begin{array}{l}\text { immediate physical } \\
\text { and psychological } \\
\text { condition, overall } \\
\text { health condition }\end{array}$ & trunk, limbs \\
\hline $\begin{array}{l}\text { Motion tracking } \\
\text { sensors }\end{array}$ & $\begin{array}{c}\text { acceleration, angle } \\
\text { of rotation, etc. }\end{array}$ & $\begin{array}{l}\text { immediate physical } \\
\text { condition, overall } \\
\text { health condition }\end{array}$ & trunk, head, limbs \\
\hline Strain gauge sensor & $\begin{array}{l}\text { force, deformation, } \\
\text { etc. }\end{array}$ & $\begin{array}{l}\text { immediate physical } \\
\text { condition, overall } \\
\text { health condition }\end{array}$ & limbs \\
\hline $\mathrm{pH}$ level sensors & $\mathrm{pH}$ level & $\begin{array}{l}\text { immediate physical } \\
\text { condition, overall } \\
\text { health condition }\end{array}$ & trunk, limbs \\
\hline Lactate level sensors & lactate level & $\begin{array}{l}\text { immediate physical } \\
\text { condition, overall } \\
\text { health condition }\end{array}$ & $\begin{array}{l}\text { trunk, limbs, oral } \\
\text { cavity, cornea }\end{array}$ \\
\hline $\begin{array}{l}\text { Glucose level } \\
\text { sensors }\end{array}$ & glucose level & $\begin{array}{l}\text { immediate physical } \\
\text { condition, overall } \\
\text { health condition }\end{array}$ & trunk, limbs, cornea \\
\hline $\begin{array}{l}\text { Other electrochemi- } \\
\text { cal sensors of } \\
\text { homeostasis }\end{array}$ & uric acid level, etc. & $\begin{array}{l}\text { overall health } \\
\text { condition }\end{array}$ & trunk, limbs \\
\hline
\end{tabular}




\subsection{Classification of Current Data Evaluation Methods}

In recent years, development in the field of wearable systems has generally focused on suitable mathematical algorithms for processing and interpretation of measured physiological and environmental signals [47-51]. In the past, a number of quantitative evaluation methods have been, independently on their eventual usage in the field of soldier wearable systems, developed for the evaluation and interpretation of the data measured by the wearable system sensors. Choosing the specific methods in practice is influenced not only by the characteristics of the processed signal, but also by the decision if the measured data must be processed online, so that one can be alerted about an imminent collapse of the organism, or they can be only gathered and processed afterwards. This has a significant influence on the computational complexity of the method. There are many ways of computing and evaluation of data, but they can be classified as follows:

\section{Methods of Evaluation of Time Domain Data}

The most frequently used methods of evaluation of data by defining parameters such as maximal value, minimal value, range of measured values, variance of the measured values of the specific measured quantity $[13,52,53]$. The determined parameter's value in specific moment in time can determine the condition of the measured subject, either by the expert evaluation of the relevant person, or automatically, based on previous measured normative values corresponding to a specific state of subject.

\section{Methods of Evaluation of Frequency Domain Data}

Evaluating data in the frequency domain using amplitude spectrum as well as power spectrum. Frequency domain evaluation is rather complex for interpretation compared to methods of evaluation of time domain data. That is why these methods are not used as often as the methods of evaluation of time domain data in the case of wearable systems. Although, the methods using the Fourier transformation or wavelet transformation are often used in specific cases, for example, in the evaluation of the heart rate, electrical activity of brain or movement activities (i.e. tremor) [54-57], where the interpretation is intuitive and taken from the common civil application.

\section{Nonlinear Methods of Data Evaluation}

Linear methods work with an assumption that every behaviour pattern in a sequence of repeated tasks is independent from the preceding and following behaviour. In contrast, nonlinear methods approach the structure of variability by analysing fluctuations in patterns in time and observe how one behaviour can affect the next one. Despite recent rise in the use of nonlinear methods, these are still a less popular choice for professionals compared to the previous methods, mainly due to the demanding processing and complexity of data interpretation [58]. These methods are not used with wearable systems in military.

\section{Methods of Evaluation of Relationship between Measured Variables}

There are many indicators in the quantitative evaluation of data based on the analysis of relations between measured variables. Generally, two or more simultaneously recorded quantities and their interdependence are evaluated. The methods, however, are not used often due to their computational complexity and intricate interpretation compared to the methods of evaluation of time domain data [59]. These methods are not used for wearable systems in military. 


\subsection{The Status of the Systems and Methods in Use in the Czech Armed Forces}

In this part, we will describe the currently used specific systems and methods in the military field in the Czech Republic with a focus on wearable systems and the corresponding methods.

\subsection{Wearable Systems}

Although many wearable sensors for monitoring heart [60], breathing [61], temperature [62], etc. were developed in the Czech Republic, none of them, apart from exceptions, are used in the military. The wearable systems are used only experimentally in the Czech Armed Forces. For example, the FlexiGuard system [13, 63] is a biotelemetric system for monitoring the physiological conditions of rescuers, firefighters and soldiers and it was developed at the Faculty of Biomedical Engineering of the Czech Technical University in Prague. The design was based on the needs of end users from the ranks of firefighters and soldiers and in direct collaboration with them. The purpose of the system is to increase the personal safety of the monitored people during training and missions: every member of the team (typically 4 to 10 people) has sensors, which are placed in their equipment (i.e. suit or under a suit) and which measure a number of biological and technical parameters and transfer these data wirelessly to the visualization unit of the commander. The basic set consists of heart rate sensors, body surface temperature sensors, motion tracking sensors (accelerometers) and perspiration (humidity) sensors.

The system can also contain respiratory rate sensors. Adding more sensors (e.g. multisensory of explosive and poisonous substances, detector of ionizing radiation, etc.) can be implemented and used by a few mouse clicks. Signal synchronization with the footage from the digital camera connected to the command visualisation unit is also possible. In Fig. 1, the monitoring kit for one person is shown. The general aim is to create a functional monitoring device in the desired form that will allow localization, monitoring of health and physiological parameters (e.g. heart rate, body surface temperature) and automatic signalization of risk conditions (e.g. physical exhaustion, overheat) of a soldier in extreme conditions. The system also allows to distinguish the nature and intensity of the movement of a soldier (e.g. laying down, standing, running, crawling), determining his actual and overall energy expenditure, including monitoring of the environmental parameters (e.g. temperature, presence of dangerous substances, humidity). The system was already tested in field conditions, but has not been implemented in practice yet. Thanks to the power saving mode, the battery life is 15 to 72 hours. Testing resistance against extreme temperatures was carried out by observing the functions of the device in environment with temperatures $-15^{\circ} \mathrm{C}$ and $+80{ }^{\circ} \mathrm{C}$. Temperature changes did not have any effect on the functionality of the sensors [13, 63]. Inside every personal measuring unit, there is a memory card that stores every input signals, even in the case of random blackout of the wireless data transmission with the command visualisation unit. Therefore, the developed system allows long-term monitoring of a soldier during a mission. A proposal to implement the system in the soldier's gear, development of the measured data evaluation methods and extensive testing in terrain is being carried out.

\subsection{Methods of Data Evaluation}

For the evaluation of the data from the wearable systems, methods of evaluation of time domain and methods of evaluation of frequency domain data are being currently used in the Czech Armed Forces. Primarily, there are the determining of the maximal value and 
the range of values of the measured quantities in specific time interval. By using the mentioned method of direct magnitude calculation of the measured quantity, we can avoid the necessity of transforming the data or calculating complex derived parameters, which greatly accelerates the data transmission and interpretation. The determined data of maximal values and ranges of values of the measured quantities are then analysed. Therefore, traditional parameters for data evaluation in time interval are used. In the context of the use of data evaluation in the frequency domain, new parameters (e.g. frequency of peak amplitude) are being tested. Using traditional parameters is given by the fact that the system is being developed in collaboration with clinical practice, which demands application of already implemented methods and verified parameters of evaluation in the wearable systems. The Czech Armed Forces thus, with the use of the wearable system, measures and evaluates heart rate, respiratory rate, body temperature and acceleration value at specific time point or time interval during the training in the field $[13,63]$. From basic parameters, with a computer wirelessly gathering data, it is possible, using the defined threshold values of the measured parameters, to determine the physical condition of the proband (e.g. reaching the anaerobic threshold, position of a segment of the body, overheat identification, energetic expenditure assumption, etc.) and to gather data about the environment he is in (e.g. dangerous substance presence, etc.). This information is presented in user-friendly interface in the command visualisation unit and it can be used, for example, for decision making, for optimization of the training course, etc. An example of the user interface is shown in Fig. 2.

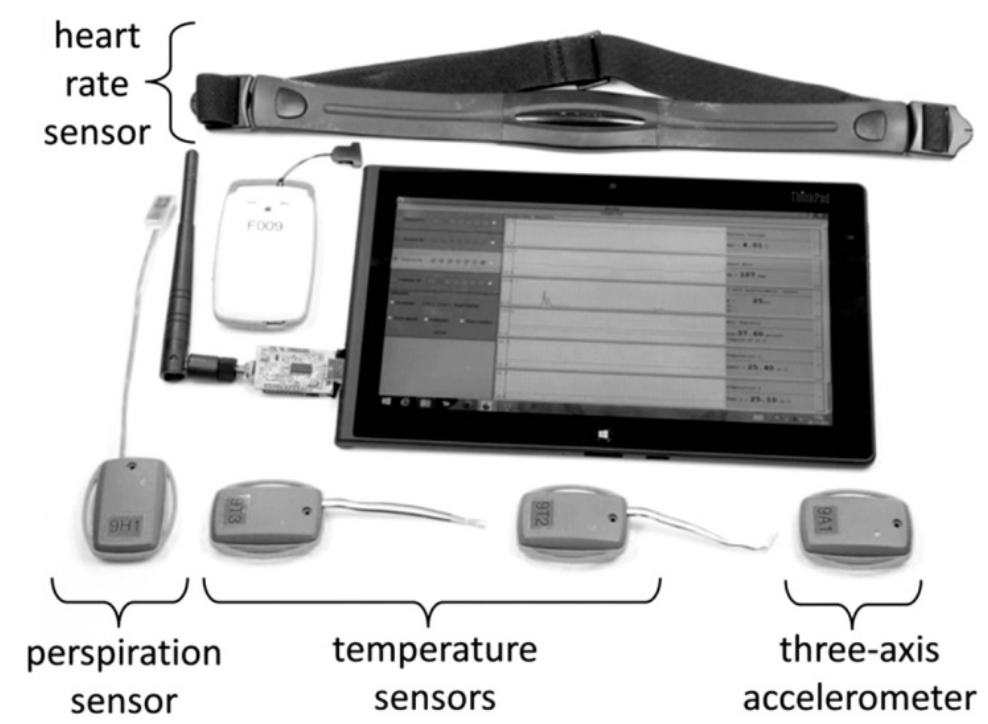

Fig. 1 Kit for monitoring the mental and physical condition of a single subject

In practice, the summary view of the resulting information in the form of "traffic lights" has proven to be the most suitable (green - everything is okay, orange - slightly higher values than the threshold, or technical difficulties, red - significantly higher values than the threshold). Apart from this summary, a complete log of signals of the monitored soldiers is being recorded. It is possible to go through it anytime, to determine the cause of the alarm, and to compare individual reactions of the subjects to the stressful situations. 


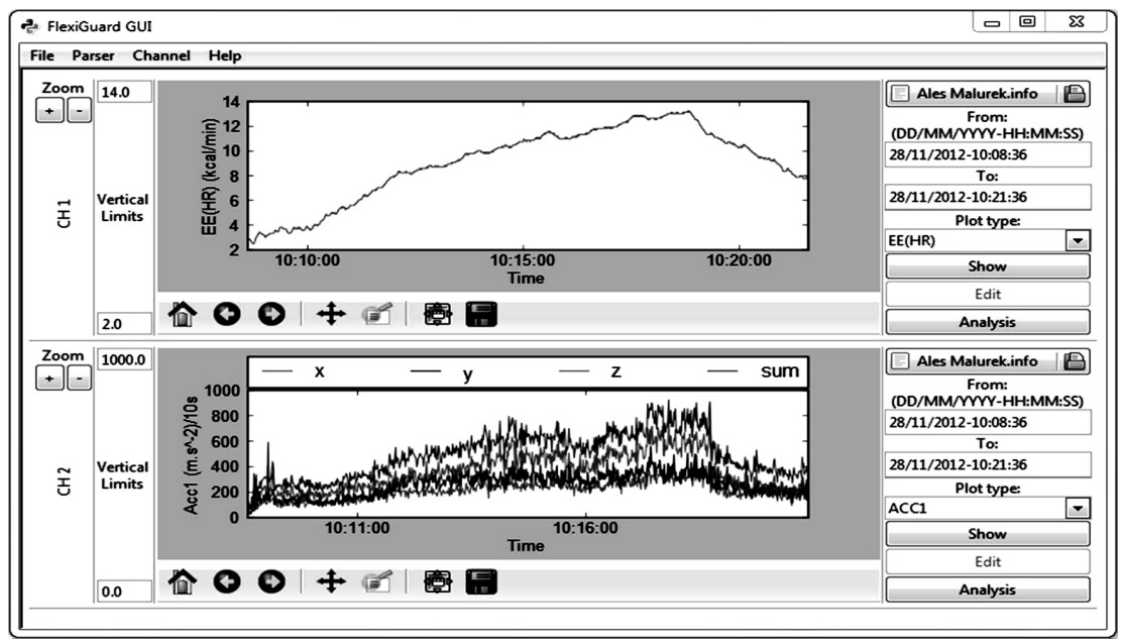

Fig. 2 Illustration of the graphical user interface with the measured data (energy expenditure (EE) and acceleration (Acc)) of a single subject

\section{Discussion}

In this part of the paper, we assess the current state of the use of specific systems and methods in the military field, focusing on wearable systems and appropriate methods, both in the world and in the Czech Republic, and we make recommendations of suitable types of systems, sensors and methods to be used in the army.

\subsection{Wearable Systems}

As mentioned before, numerous research projects were devoted to the design of generalpurpose or medical BNS solutions in the last decade; moreover, new research projects have recently been launched. However, based on the background research done and the mentioned description, up to our knowledge, there is no serious publicly available research in the area of military BSNs. In recent years, the development in the field of wearable systems generally focused on increasing the number of different types of sensors enabling to monitor physiological, behavioural and environmental parameters. It also focused on the development of improved usability, ergonomics and robustness of the system against harsh environments. Beside the general challenges related to BSNs, such as security, reliability, energy efficiency and robustness against external interferences, the specific context of military applications introduces new design constraints and research challenges in comparison with civilian BSN solutions. Units of the armed forces are generally deployed in harsh environments and require effective communication to transmit real-time information to their command centre for proper decision making. Thus, military BSNs, not relying on pre-existing network infrastructures, are capable of operating in the case of unavailable or overloaded local network (e.g. $3 \mathrm{G}$, LTE) and data are still transmitted from the deployed mobile units to the command centre. Generally, it applies that military systems are similar to the ones used in civilian sphere, but more resistant to interference and with longer service life. Regarding the article topic, we will focus on the appropriateness of specific sensors of the wearable systems for military use. 


\subsection{Sensors of Wearable Systems}

The current development of sensor application is focused on possibilities of suitable technical placement (e.g. comestible temperature-measuring pills, "smart" chest straps, hats or shirts, new textile materials). The aim of research teams is also the development of very small biocompact sensors of physiological parameters, which will be implantable under skin or attached to the surface of a mucous membrane, for example, in the digestive system [51]. This overview shows the use of specific wearable sensors in the world, as well as in the military, and it describes their advantages and disadvantages.

\section{Heart Rate Sensors}

Basic sensor that has been already used for monitoring soldiers in practice. Due to the capability of monitoring vital functions and small dimensions, it can be assumed that it will be further used in the wearable systems.

\section{Electrocardiogram Sensors}

Used only experimentally. Due to the complexity of the measured data, which are more demanding on interpretation, it is not assumed that they will be used in practice. However, they are and will be standardly used in larger medical facilities. It is assumed that the wearable sensors will be used only during training with the following evaluation of experienced medical personnel, or, in the future, in a decision support system or a complex expert system.

\section{Electroencephalography Sensors}

Not used in practice in the wearable systems, only experimentally in hospital laboratories and home environment. Due to the complexity of the measured data, which are more demanding on interpretation, it is not assumed that they will be used in practice. It is assumed that the wearable sensors will be used only during training with the following evaluation of experienced medical personnel, or, in the future, in a decision support system or a complex expert system.

\section{Respiratory Rate Sensors}

Basic sensor that is used for monitoring soldiers, used in practice. Due to the capability of monitoring vital functions, it can be assumed that it will be further used in the wearable systems. With other sensors, it will form the basis for monitoring the condition of the individual in conjunction with simple expert systems.

\section{Blood pressure Sensors}

Already used in wearable system, but it is a space-demanding type of sensor. Due to the possibility of monitoring not only the heart function, but also the circulatory system, it can be assumed that if the size gets minimized, it will be widely used. Basic expert system can determine health condition of a soldier using the data from the system.

\section{Pulse oximetry Sensors}

Used only experimentally in wearable systems. The sensor can complement the heart rate sensor with data about circulatory system. Due to the more demanding evaluation of data, and therefore the necessity of an expert evaluation or more complex expert system, it can be assumed that the system will be used primarily in medical facilities.

\section{Other Photoplethysmographic Sensors}

Used only experimentally in wearable systems. Sensors can monitor, for example, the circulatory system and complement other vital-functions sensors. Due to the more demanding evaluation of data, and therefore the necessity of an expert evaluation or more complex expert system, it can be assumed that the system will be used primarily in medical facilities or in combat vehicle cabs, but not in the "smart" suits of soldiers. 


\section{Thoracic Electrical Bioimpedance Sensors}

Used only experimentally. Due to the complexity of measurement, larger system size and measured data that are more demanding on interpretation, it is not assumed that they will be intensively used in field conditions. Neither their use in large medical facilities is standard. It is assumed that the wearable sensors will be used only during training with the following evaluation of experienced medical personnel.

\section{Electrooculography Sensor / Eyeblink Sensor}

Used only experimentally in wearable systems. The sensor can complement sensors such as heart rate sensor and respiratory sensors. Due to the minimal use in the wearable systems, no suitable evaluation methods exist. It is, however, possible to use them in the already used helm-implemented systems, for example, as a component of a micro cameras that evaluate the activity of soldiers during training.

\section{Acoustic Sensors}

Used only experimentally in wearable systems. The sensor can complement sensors such as heart rate sensors and respiratory sensors. Due to the simplicity of structure and compactness, it can be used in field conditions. Already existing system that is part of the gear, for example, a microphone for communication can be used for the data recording. However, the automatic identification of the condition of the soldier is very difficult. A complex expert system, which has not been developed yet, or expert personnel is needed.

\section{Electromyography Sensors}

Used only experimentally in wearable systems. The sensors are not monitoring vital functions, but can monitor the condition of the musculoskeletal system. The sensors are space-demanding, and therefore the system will be used only in larger medical facilities. The next disadvantage of these sensors is difficult quantification of the measured signal [64]. To overcome some shortcomings, researchers are developing sensors that can measure other physical characteristics of muscles (e.g. muscle force). In future, it can be used for controlling actuators in exoskeletons.

\section{Temperature Sensors}

Used very frequently in wearable systems. The sensors do not monitor any vital function, but can complement vital function sensors and, based on body temperature and information such as heart rate, determine the load on organism. Evaluation can be done by expert personnel and it can be assumed that the sensor will become a basic type of sensors in wearable systems.

\section{Galvanic Skin Response Sensors}

Used only experimentally. Due to the complexity of the measured data, which are more demanding on interpretation, it is not assumed that they will be used in practice. Neither their use in large medical facilities is standard. It is assumed that the wearable sensors will be used only during training with the following evaluation by experienced medical personnel.

\section{Perspiration Sensors}

Used only experimentally. The sensor does not monitor any vital function, but can complement vital function sensors and, based on sweat intensity and information such as heart rate, determine the load on organism. Evaluation can be done by expert personnel or system and it can be assumed that the sensor will be used in wearable systems.

\section{Motion Tracking Sensors}

Very common in wearable systems. The sensor does not monitor any vital function, but can complement vital function sensors and, based on the intensity of movement of selected segments of the body and information such as heart rate, determine the load on 
organism. Evaluation can be done by expert personnel or system and it can be assumed that the sensor will continue to be a basic type of wearable system sensors. Another reason why it is expected to be further used is that it allows to determine the way of fighting, movement on the battlefield, etc.

\section{Strain Gauge Sensors}

Used only experimentally in wearable systems. The sensor does not monitor any vital function, but can complement vital function sensors and, based on the movement of the lower limbs, determine the load on organism. Evaluation can be done by expert personnel or system and it can be assumed that the sensor will continue to be a basic type of wearable system sensors. Another reason why it is expected to be further used is that it allows to determine the way of fighting, movement on the battlefield, etc.

\section{pH Level Sensors}

Used only experimentally. The sensors do not monitor any vital function, but can complement vital function sensors and, based on the $\mathrm{pH}$ of the skin, determine the long-term medical condition. Therefore, they are not suitable for wearable systems, but for use in larger medical facilities within the framework of training.

\section{Lactate Level Sensors}

Used only experimentally. On the basis of the data, the stress level, physical exhaustion and physical capabilities can be estimated. Due to the complexity of data acquisition, it is not assumed that they will be used in practice; they will probably rather be used only during training.

\section{Glucose Level Sensors}

The sensors monitor physical exhaustion and the information about the glucose level helps to better interpret, for example, the data from the galvanic skin response sensors, because hypoglycaemia causes excessive sweating. Due to the complexity of data acquisition, it is not assumed that they will be used in practice; however, they will be used only during training.

\section{Other Electrochemical Sensors of Homeostasis}

Not used in wearable systems. Due to the more demanding recording and evaluation of data, it can be assumed that the system will be used primarily in medical facilities or in combat vehicle cabs, but not in the field.

In summary, the crucial characteristics of sensors in wearable military systems are sensor size, sensor placement, simplicity of data acquisition, difficulty or absence of data interpretation. Military sensors face many of the same challenges as their medical counterparts in civilian sphere, such as e.g. being comfortable to wear for many hours, easy attachment to the body, or others. In addition, military sensors must be reliable and durable despite harsh environment.

\subsection{Methods of Data Evaluation Measured by Wearable Systems}

Studies show that wearable systems are suitable and relatively precise for monitoring basic physiological quantities, but monitoring other parameters is either inaccurate or unpractical from the operational point of view, for example, monitoring of hydration. Monitoring systems have certain weak spots, primarily in the interpretation and evaluating the measured data. Although BSNs can produce vast amounts of raw data, it is necessary to employ methods that convert this raw data into usable knowledge in an efficient manner. However, it can be generally said that most of the algorithms for evaluation and interpretation of the measured physiological signals is relatively rudimentary 
and in need of a future development with the support of clinical experts. It is also important to consider the fact that every individual has slightly different natural values of physiological functions, which can be problematic for the evaluation and threshold determination. Therefore, it is necessary to emphasize the use of personalized medicine within the meaning of the individualization of the "standard" for each individual and track changes to the "standard". An overview of the methods for the evaluation and interpretation of measured data from the various sensors, which indicated their possible use in military applications and which points out their advantages and disadvantages, is listed below.

\section{Methods of Evaluation of Time Domain Data}

Since they are the most commonly used methods and the interpretation is simple, assuming utilization of expert knowledge, for example, in the case of comparing measured and expected values of parameters, it can be assumed that they will continue to be intensively used in portable systems. In the future, it is expected, that the data evaluation will be automated and parameter values, gathered by different types of sensors, will be evaluated simultaneously by a system based on, for example, neural networks or fuzzy logic. On the basis of multiple inputs, an index determining the physical and psychological conditions of the subjects will be deducted. Therefore, there will be no need for an expert or expert system evaluating each of the parameters independently.

\section{Methods of Evaluation of Frequency Domain Data}

This is the second most frequently used method of evaluation. However, it needs a record of multiple values (values in longer time interval), and therefore is more demanding on memory and computing power, which can be a problem in the case of cheap miniaturized sensors. Nevertheless, thanks to the miniaturization and improvement of technical possibilities of modern sensors, we can assume a wider application in the future. Based on the distribution of measured data in the frequency domain and distribution presupposed by an expert, a physical and psychological condition of a soldier can be deduced. In conjunction with the methods of evaluation of time domain data, the deduction can be more precise. By aggregating information from different sensors, a single index of the physical and psychological conditions of a soldier can be directly deduced.

\section{Nonlinear Methods of Data Evaluation}

Methods which are more demanding on data processing and interpretation. The data evaluation is very demanding on memory and system computing power; that is why they are not commonly used. But with the improving of technical possibilities, they could be applied more. Data interpretation may be based on expert system that uses artificialintelligence methods, which would reduce the operating requirements of the system. We can expect extensions of these methods for the wearable systems, where they can provide more accurate or new information if compared with the methods of evaluation of time and frequency domain data. However, the methods of evaluation of time and frequency domain data are verified and widely used, while the nonlinear methods will be seldom used, also because the number of suitable sensors for military wearable systems is very limited.

\section{Methods of Evaluation of Relationship between Measured Variables}

As in the case of nonlinear methods of data evaluation, the methods of evaluation of relationship between measured variables are also more demanding on processing and interpretation. Therefore, these methods will be likely used in specifically focused larger facilities, for example, during training and following expert evaluation by the methods in the hospital, and not in the wearable systems in field conditions. 
Generally, we can say that most of the algorithms for processing and interpretation of measured physiological signals is relatively rudimentary and in need of a future development with the support of clinical experts [65]. When choosing the method for processing the measured data, it is necessary to consider the specific applications. For example, in the case of evaluation of current physical and psychological conditions of a soldier on a battlefield, the speed of the data processing is the essential requirement of the method, and therefore the methods of evaluation of time domain data will be primarily used.

\subsection{Recommendations Concerning Sensors and Methods for Wearable Systems}

From the above mentioned, it is clear that not all systems or sensors are suitable for use in combat conditions and demanding environment. In the case of the expected usage of the wearable system, the options to measure specific biomedical data for determining the physical and psychological conditions of an individual are reduced. The following table shows an overview of the systems and their suitability for the use in specific environment (Tab. 2). It is necessary to bear in mind that the chosen types of sensors determine, in accordance with the application and usage in Tab.1, the suitability of the wearable system for the army application.

The actual methods of data evaluation are not limited by the options of their use, but it is necessary to consider their computational complexity, necessary volume and the form of recorded data, baud rate, etc. Some methods need longer data recording time for the determination of the specific quantitative index, this can be a problem, for example, in the case of miniature system with a limited memory. Another limitation is the meaningfulness of their use. When choosing methods for data evaluation for the wearable systems, we often come across some limitations, such as baud rate, memory capacity, etc. Because of this, methods which are not so computationally demanding of evaluation of time domain data are more suitable. It is usually a direct and immediate comparison of the measured values with bandwidth values (i.e. value zones), which are defined by an expert, corresponding to a specific condition of the subject. Or, if necessary, short records of the measured data are evaluated by methods of evaluation of frequency domain data. When choosing specific method, it is necessary to reach a compromise between the demands of the specific parameters and the measuring system capabilities. We can expect, with increasing computational power of subsystems of the measuring systems and miniaturization of their electronic components, the use of more computational demanding methods. But there could be a problem that users (the supervisory staff that evaluates the conditions of soldiers based on more complex methods) will be overloaded with information and there will be a problem with effective interpretation of the parameters measured by complex methods. It is suitable to use basic methods and a limited number of sensors that suffice for the determination of the condition of the measured subject. Otherwise, it would be necessary to use fully, or semi-automated expert system that would allow to reduce the load on the operator monitoring the conditions of soldiers.

\section{Conclusion}

From the analysis of various types of wearable systems their sensors and methods of data evaluation given in the paper, it is obvious that, in most cases, the systems and methods designed for the civilian sphere can be used for determining the condition of 
Tab. 2. Overview of suitability of respective systems for a long-term use in a specific military environment

\begin{tabular}{|c|c|c|c|c|}
\hline $\begin{array}{l}\text { Sensor } \\
\text { type }\end{array}$ & $\begin{array}{l}\text { Diagnostics } \\
\text { in hospitals }\end{array}$ & $\begin{array}{c}\text { Diagnostics in } \\
\text { small field } \\
\text { medical } \\
\text { centres }\end{array}$ & $\begin{array}{c}\text { Diagnostics in } \\
\text { combat } \\
\text { vehicles and } \\
\text { military means } \\
\text { of transport }\end{array}$ & $\begin{array}{l}\text { Diagnostics in } \\
\text { individuals in } \\
\text { field } \\
\text { independently }\end{array}$ \\
\hline Heart rate sensors & suitable & suitable & suitable & suitable \\
\hline $\begin{array}{c}\text { Electrocardiogram } \\
\text { sensors }\end{array}$ & suitable & suitable & suitable & less suitable \\
\hline $\begin{array}{c}\text { Electroencephalog- } \\
\text { raphy sensors }\end{array}$ & suitable & suitable & suitable & less suitable \\
\hline $\begin{array}{c}\text { Respiratory rate } \\
\text { sensors }\end{array}$ & suitable & suitable & suitable & suitable \\
\hline $\begin{array}{c}\text { Blood pressure } \\
\text { sensors }\end{array}$ & suitable & suitable & suitable & less suitable \\
\hline $\begin{array}{c}\text { Pulse oximetry } \\
\text { sensors }\end{array}$ & suitable & suitable & suitable & suitable \\
\hline $\begin{array}{l}\text { Other photoplethys- } \\
\text { mographic sensors }\end{array}$ & suitable & suitable & less suitable & less suitable \\
\hline $\begin{array}{c}\text { Thoracic electrical } \\
\text { bioimpedance } \\
\text { sensors }\end{array}$ & suitable & suitable & less suitable & less suitable \\
\hline $\begin{array}{c}\text { Electrooculography } \\
\text { sensor/eyeblink } \\
\text { sensor } \\
\end{array}$ & suitable & suitable & less suitable & less suitable \\
\hline Acoustic sensors & suitable & suitable & suitable & suitable \\
\hline $\begin{array}{c}\text { Electromyography } \\
\text { sensors } \\
\end{array}$ & suitable & suitable & less suitable & less suitable \\
\hline $\begin{array}{c}\text { Temperature } \\
\text { sensors }\end{array}$ & suitable & suitable & suitable & suitable \\
\hline $\begin{array}{c}\text { Galvanic skin } \\
\text { response sensors }\end{array}$ & suitable & suitable & $\begin{array}{l}\text { highly limited } \\
\text { use }\end{array}$ & unsuitable \\
\hline $\begin{array}{c}\text { Perspiration } \\
\text { sensors }\end{array}$ & suitable & suitable & $\begin{array}{c}\text { highly limited } \\
\text { use }\end{array}$ & $\begin{array}{c}\text { highly limited } \\
\text { use }\end{array}$ \\
\hline $\begin{array}{l}\text { Motion tracking } \\
\text { sensors }\end{array}$ & suitable & suitable & suitable & suitable \\
\hline $\begin{array}{c}\text { Strain gauge } \\
\text { sensor }\end{array}$ & suitable & suitable & suitable & suitable \\
\hline $\mathrm{pH}$ level sensors & suitable & suitable & less suitable & unsuitable \\
\hline $\begin{array}{c}\text { Lactate level } \\
\text { sensors }\end{array}$ & suitable & suitable & less suitable & less suitable \\
\hline $\begin{array}{c}\text { Glucose level } \\
\text { sensors }\end{array}$ & suitable & suitable & less suitable & less suitable \\
\hline $\begin{array}{c}\text { Other electrochemi- } \\
\text { cal sensors of } \\
\text { homeostasis }\end{array}$ & suitable & suitable & $\begin{array}{l}\text { highly limited } \\
\text { use }\end{array}$ & unsuitable \\
\hline
\end{tabular}


a soldier during a mission. Several methods for monitoring physical and health conditions of a subject have been developed in civilian sphere and a very small portion of them was used in the military environment. It was mostly just the basic sensors and oldest methods of quantitative data evaluation. The reason for this is that research in this area is in the army primarily focused on application in specific fields of use, where the already established and in the civilian sphere verified systems and methods are used. In the field of wearable systems, a further development and testing in real conditions, focused on the ergonomic and evaluation aspects, is necessary. The article should, by introducing the possibility of other types of sensors and methods, assist in the selection and application of these wearable systems and methods in military environment.

\section{References}

[1] SHNAYDER, V., CHEN, B., LORINCZ, K., FULFORD-JONES, T. and WELSH, M. Sensor Networks for Medical Care. In Harvard University Technical Report TR-08-05. Cambridge: Harvard University, 2005.

[2] SHELTAMI, T., MAHMOUD, A. and ABU-AMARA, M. Warning and Monitoring Medical System Using Sensor Networks. In Proceedings of the Saudi $18^{\text {th }}$ National Computer Conference (NCC18), 2006, p. 26-29.

[3] Continuous Mobile Services for Healthcare [on line]. [cited 2017-01-04]. Available from: <http://www.healthservice24.com>.

[4] GAO, T. et al. The Advanced Health and Disaster Aid Network: A Light-weight Wireless Medical System for Triage. IEEE Transactions on Biomedical Circuits and Systems, 2007, vol. 1, no. 3, p. 203-216. DOI 10.1109/TBCAS.2007.910901.

[5] JANTUNEN, I. et al. Smart Sensor Architecture for Mobile-terminal-centric Ambient Intelligence. Sensors and Actuators A: Physical, 2008, vol. 142, no. 1, p. 352-360. DOI 10.1016/j.sna.2007.04.014.

[6] WAC, K. et al. Mobile Patient Monitoring: the MobiHealth System. In Engineering in Medicine and Biology Society, 2009. EMBC 2009. Annual International Conference of the IEEE. IEEE, 2009, p. 1238-1241.

DOI 10.1109/IEMBS.2009.5333477.

[7] FARELLA, E. et al. Interfacing Human and Computer with Wireless Body Area Sensor Networks: the WiMoCA Solution. Multimedia Tools and Applications, 2008, vol. 38, no. 3, p. 337-363. DOI 10.1007/s11042-007-0189-5.

[8] JIANG, S. et al. CareNet: An Integrated Wireless Sensor Networking Environment for Remote Healthcare. In Proceedings of the ICST $3^{\text {rd }}$ International Conference on Body Area Networks. Institute for Computer Sciences, Social-Informatics and Telecommunications Engineering, 2008, p. 9. ISBN 978-9639799-17-2

[9] CURTIS, D. et al. Physiological Signal Monitoring in the Waiting Areas of an Emergency Room. In Proceedings of the ICST $3^{\text {rd }}$ International Conference on Body Area Networks. ICST, 2008, p. 5. ISBN 978-963-9799-17-2.

[10] Wear-a-BAN - Unobtrusive Wearable Human to Machine Wireless Interface [on line]. [cited 2017-01-04]. Available from <http://www.wearaban.com>.

[11] Help4Mood [on line]. [cited 2017-01-04]. Available from:

$<$ http://www.help4mood.info $>$.

[12] WearIT@work Project [on line]. [cited 2017-01-04]. Available from: $<$ http://www.wearitatwork.com>. 
[13] SCHLENKER, J. et al. FlexiGuard: Modular Biotelemetry System for Military Applications. In 2015 International Conference on Military Technologies. Brno: IEEE, 2015, p. 1-6. DOI 10.1109/MILTECHS.2015.7153712.

[14] CORMORAN Project Exploring Ways to Improve Cooperation In and between Wireless Body Area Networks [on line]. Communications of the ACM. [cited 2017-04-01]. Available from: <http://cacm.acm.org/news/165000-cormoranproject-exploring-ways-to-improve-cooperation-in-and-between-wireless-bodyarea-networks/fulltext $>$.

[15] CURONE, D. et al. Smart Garments for Emergency Operators: the ProeTEX Project. IEEE Transactions on Information Technology in Biomedicine, 2010, vol. 14, no. 3, p. 694-701. DOI 10.1109/TITB.2010.2045003.

[16] HALL, P.S. et al. Antennas and Propagation for Body-Centric Wireless Network. $2^{\text {nd }}$ edition. P.S. Hall, Y. Hao (editors), Boston: Artech Hosue, 2012, p. 586-589.

[17] AKYILDIZ, I.F. et al. A Survey on Sensor Networks. IEEE Communications magazine, 2002, vol. 40, no. 8, p. 102-114. DOI 10.1109/MCOM.2002.1024422.

[18] LIM, HB. et al. A Soldier Health Monitoring System for Military Applications. In Body Sensor Networks (BSN), 2010 International Conference on Body Sensor Networks. IEEE, 2010, p. 246-249. DOI 10.1109/BSN.2010.58.

[19] JAISWAR, D. and REPAL, S.S. Real Time Tracking and Health Monitoring of Soldiers using ZigBee Technology: A Survey. International Journal of Innovative Research in Science, Engineering and Technology, 2015, vol. 4, no. 7. DOI 10.15680/IJIRSET.2015.0407100.

[20] NIKAM, S. et al. GPS Based Soldier Tracking and Health Indication System. International Journal of Advanced Research in Electrical, Electronics and Instrumentation Engineering, 2013, vol. 2, no. 3. ISSN 2320-3765.

[21] PRAMOD, P. GPS Based Advanced Soldier Tracking with Emergency Messages \& Communication System. International Journal of Advance Research in Computer Science and Management Studies Research Article, 2014, vol. 2, no. 6. ISSN 2091-2730.

[22] JAVAID, N. et al. Measuring fatigue of soldiers in wireless body area sensor networks. In Broadband and Wireless Computing, Communication and Applications (BWCCA), 2013 Eighth International Conference on. IEEE, 2013. p. 227231. DOI 10.1109/BWCCA.2013.43.

[23] KIM, Y.S. et al. Helmet-based Physiological Signal Monitoring System. European Journal of Applied Physiology, 2009. vol. 105, no. 3, p. 365-372. DOI 10.1007/s00421-008-0912-6.

[24] KIM, Y.S. et al. ECG, EOG Detection from Helmet Based System. In Information Technology Applications in Biomedicine, 2007. $6^{\text {th }}$ International Special Topic Conference on Information Technology Applications in Biomedicine. IEEE, 2007, p. 191-193. DOI 10.1109/ITAB.2007.4407378.

[25] PRAKASH, P. and ADINARAYANA, T.V.S. A Novel Approach of SensorsBased Wearable Systems for Monitoring of Human Movement and Falls. International Journal of Science and Research (IJSR), 2014. vol. 3, no. 7. ISSN 2319-7064. 
[26] PANTELOPOULOS, A. and BOURBAKIS, NG. A Survey on Wearable Sensorbased Systems for Health Monitoring and Prognosis. IEEE Transactions on Systems, Man, and Cybernetics, Part C (Applications and Reviews), 2010, vol. 40, no. 1, p.1-12. DOI 10.1109/TSMCC.2009.2032660.

[27] LLORET, J. Introduction to Practical Deployments on Wireless Sensor Networks. International Journal on Advances in Networks and Services, 2010. vol. 3 , no. $1 \& 2$.

[28] DARWISH, A. and HASSANIEN, A.E. Wearable and Implantable Wireless Sensor Network Solutions for Healthcare Monitoring. Sensors, 2011. vol. 11, no. 6, p. 5561-5595. DOI 10.3390/s110605561.

[29] BRANCHE, P.C. et al. Measurement Reproducibility and Sensor Placement Considerations in Designing a Wearable Pulse Oximeter for Military Applications. In Bioengineering Conference, 2004. Proceedings of the IEEE $30^{\text {th }}$ Annual Northeast. IEEE, 2004. p. 216-217. DOI 10.1109/NEBC.2004.1300072.

[30] MENDELSON, Y., DUCKWORTH, R.J. and COMTOIS, G. A Wearable Reflectance Pulse Oximeter for Remote Physiological Monitoring. In Engineering in Medicine and Biology Society, 2006. EMBS'06. $28^{\text {th }}$ Annual International Conference of the IEEE. IEEE, 2006, p. 912-915.

DOI 10.1109/IEMBS.2006.260137.

[31] TAMURA, T. et al. Wearable Photoplethysmographic Sensors - Past and Present. Electronics, 2014, vol. 3, no. 2, p. 282-302.

DOI 10.3390/electronics3020282.

[32] BERA, T.K. Bioelectrical Impedance Methods for Noninvasive Health Monitoring: A Review. Journal of Medical Engineering, 2014.

DOI 10.1155/2014/381251.

[33] SHAW, G.A. et al. Warfighter Physiological and Environmental Monitoring: A Study for the US Army Research Institute in Environmental Medicine and the Soldier Systems Center [Final Report]. Massachusetts Institute of Technology Lincoln Laboratory, 2004.

[34] KALE, S.D. and BHUYAR, D.L. A Review on WBANs Measuring Fatigue of Soldiers and Different Protocols. International Journal of Advanced Research in Electrical, Electronics and Instrumentation Engineering, 2016, vol. 5, no. 3. DOI 10.15662/IJAREEIE.2016.0503035.

[35] PERALA, C.H. and STERLING, B.S. Galvanic Skin Response as a Measure of Soldier Stress. Army Research Lab Aberdeen Proving Ground Md Human Research and Engineering Directorate, 2007.

[36] SOLOVEI, D. et al. The Development of Portable System for Unobtrusive Perspiration Monitoring. Procedia Engineering, 2012, vol. 47, p. 200-203. DOI 10.1016/j.proeng.2012.09.118.

[37] SOLOVEI, D. et al. Chemical Sensor Platform for non-invasive monitoring of activity and dehydration. Sensors, 2015. vol. 15, no. 1, p. 1479-1495. DOI 10.3390/s150101479.

[38] VASHIST, S.K. Non-invasive Glucose Monitoring Technology in Diabetes Management: A Review. Analytica Chimica Acta, 2012, vol. 750, p. 16-27. DOI 10.1016/j.aca.2012.03.043. 
[39] SAGAHYROON, A. et al. Monitoring Patients' Signs Wirelessly. Journal of Medical Imaging and Health Informatics, 2011, vol. 1, no. 3, p. 252-255. DOI 10.1109/MECBME.2011.5752121.

[40] KIM, J. et al. Non-invasive Mouthguard Biosensor for Continuous Salivary Monitoring of Metabolites. Analyst, 2014, vol. 139, no. 7, p. 1632-1636. DOI 10.1039/c3an02359a.

[41] THOMAS, N., LÄHDESMÄKI, I. and PARVIZ, B.A. A Contact Lens with an Integrated Lactate Sensor. Sensors and Actuators B: Chemical, 2012, vol. 162 no. 1, p. 128-134. DOI 10.1016/j.snb.2011.12.049.

[42] KHODAGHOLY, D. et al. Organic Electrochemical Transistor Incorporating an Ionogel as a Solid State Electrolyte for Lactate Sensing. Journal of Materials Chemistry, 2012, vol. 22, no. 10, p. 4440-4443. DOI 10.1039/C2JM15716K.

[43] IGUCHI, S. et al. A Flexible and Wearable Biosensor for Tear Glucose Measurement. Biomedical Microdevices, 2007, vol. 9, no. 4, p. 603-609. DOI 10.1007/s10544-007-9073-3.

[44] WINDMILLER, J.R. et al. Stamp Transfer Electrodes for Electrochemical Sensing on Non-planar and Oversized Surfaces. Analyst, 2012, vol. 137, no. 7, p. 1570-1575. DOI 10.1039/c2an35041f.

[45] GUINOVART, T. et al. A Potentiometric Tattoo Sensor for Monitoring Ammonium in Sweat. Analyst, 2013, vol. 138 no. 22, p. 7031-7038. DOI 10.1039/c3an01672b.

[46] BANDODKAR, A.J. et al. Epidermal Tattoo Potentiometric Sodium Sensors with Wireless Signal Transduction for Continuous Non-invasive Sweat Monitoring. Biosensors and Bioelectronics, 2014, vol. 54, p. 603-609. DOI 10.1016/j.bios.2013.11.039.

[47] BULLER, M.J. et al. Real-time Core Body Temperature Estimation from Heart Rate for First Responders Wearing Different Levels of Personal Protective Equipment. Ergonomics, 2015, vol. 58, no.11, p. 1830-1841. DOI 10.1080/00140139.2015.1036792.

[48] KEARNS, W.D., et al. Tortuosity in Movement Paths is Related to Cognitive Impairment. Methods Inf. Med, 2010, vol. 49, no. 6, p. 592-598. DOI 10.3414/ME09-01-0079.

[49] QUATIERI, T.F. and MALYSKA, N. Vocal-source Biomarkers for Depression: A Link to Psychomotor Activity. Interspeech [on line]. 2012, p. 10591062. [cited 2016-10-05]. Available from:

$<$ https://www.ll.mit.edu/mission/cybersec/publications/publication-files/full_papers/2012_09_09_MalyskaN_Interspeech_FP.pdf>.

[50] CLEMENTS, C.M. et al. Loaded and Unloaded Foot Movement Differentiation Using Chest Mounted Accelerometer Signatures. In Body Sensor Networks (BSN), 2013 IEEE International Conference on. IEEE, 2013. p. 1-5. DOI 10.1109/BSN.2013.6575524.

[51] FRIEDL, K.E. et al. Real Time Physiological Status Monitoring (RT-PSM): Accomplishments, Requirements, and Research Roadmap [on line], 2016. Army Research Inst. of Environmental Medicine Natick MA Biophysics and Biomedical Modeling div. [cited 2016-10-08]. Available from: <http://www.dtic.mil/cgibin/GetTRDoc?AD=ADA630142>. 
[52] QU, X. and YEO, J. Effects of Load Carriage and Fatigue on Gait Characteristics. Journal of biomechanics, 2011, vol. 44, no. 7, p. 1259-1263. DOI 10.1016/j.jbiomech.2011.02.016.

[53] CHU, Y. et al. Minimal Additional Weight of Combat Equipment Alters Air Assault Soldiers' Landing Biomechanics. Military Medicine, 2010, vol. 175, no. 1, $41 \mathrm{p}$.

[54] HAO, Y. and FOSTER, R. Wireless Body Sensor Networks for Health-monitoring Applications. Physiological Measurement, 2008, vol. 29, no. 11, 27 p. DOI 10.1088/0967-3334/29/11/R01.

[55] HESS, C.W. and PULLMAN, S.L. Tremor: Clinical Phenomenology and Assessment Techniques. Tremor and other Hyperkinetic Movements, 2012. DOI 10.7916/D8WM1C41.

[56] XU, H., et al. Wearable Sensor-Based Human Activity Recognition Method with Multi-Features Extracted from Hilbert-Huang Transform. Sensors, 2016, vol. 16, no. 12, 2048 p. DOI 10.3390/s16122048.

[57] NAJARIAN, K. et al. Method and Apparatus for Determining Heart Rate Variability Using Wavelet Transformation. U.S. Patent Application No 13/140,165, 2009.

[58] SCHIFFMAN, J.M. et al. Nonlinear Analysis of Gait Kinematics to Track Changes in Oxygen Consumption in Prolonged Load Carriage Walking: A Pilot Study. Journal of Biomechanics, 2009. vol. 42, no. 13, p. 2196-2199. DOI 10.1016/j.jbiomech.2009.06.011.

[59] MEIJER, R. et al. Markedly Impaired Bilateral Coordination of Gait in Poststroke Patients: Is this Deficit Distinct from Asymmetry? A Cohort Study. Journal of Neuroengineering and Rehabilitation, 2011, vol. 8, no. 1, 23 p. DOI 10.1186/1743-0003-8-23.

[60] PARAK, J., DVORAK, J. and HAVLIK, J. Device for Long Term Measurement of Heart Rate. In Proceedings of the $4^{\text {th }}$ International Symposium on Applied Sciences in Biomedical and Communication Technologies. ACM, 2011, p. 19.

[61] STORK, M. and TOLAR, D. Wireless Electronic Systems for Physiological Parameters Measuring. In Applied Electronics (AE), 2014 International Conference on. IEEE, 2014. p. 281-284.

[62] TOLAR, D. et al. Wireless System for Monitoring Body Temperature. In $7^{\text {th }}$ WACBE World Congress on Bioengineering 2015. Springer, 2015, p. 150-153.

[63] HON, Z. et al. A Surveillance System for Enhancing the Safety of Rescue Teams, Komunikácie, 2015, vol. 17, no. 1, p. 81-86.

[64] ROSEN, J. and PERRY, J.C. Upper Limb Powered Exoskeleton. International Journal of Humanoid Robotics, 2007, vol. 4, no. 3, p. 529-548.

[65] SAQUIST, T.F. Remote Physiological Health and Status Monitoring of First Responders: Promises, Practicalities, and Prospects. Sanquist: U.S. Department of Energy, Pacific Northwest National Laboratory, 46 p. [on line]. [cited 2016-10-07]. Available from:

$<$ http://nwrtc.pnnl.gov/PDFs/RemotePhysiologicalHealthandStatusMonitoringofFirstRespondersR13.pdf $>$. 